\title{
What is an Ethical Chemist?
}

\author{
Jeffrey Kovac*
}

\begin{abstract}
Almost all decisions made by chemists, and all other scientists, in their professional lives have an ethical dimension. In both the practice of chemistry and the education of students it is essential that chemists understand the moral complexity of real-world situations, apply the relevant moral standards, and have the moral courage to make difficult choices, or the foundation of trust essential to the scientific enterprise will erode. In this lecture I will develop the fundamental concepts of scientific ethics and show how they apply to both the practice of chemistry and the relationship between chemistry and society. I will consider both day-to-day ethical problems such as authorship and the treatment of data and larger questions such as the choice of research problems and the social responsibility of scientists.
\end{abstract}

Keywords: Chemical ethics

The following is the text of a lecture delivered at six Swiss universities in late October and early November 2016. The lecture series was sponsored by the «Platform Chemistry» of the Swiss Academy of Sciences (SCNAT). Lectures were delivered at the University of Zurich, University of Geneva, EPFL (Lausanne), ETH (Zurich), University of Fribourg and the University of Basel.

It is a singular honor for me to be the inaugural lecturer in this new program. I want to congratulate the «Platform Chemistry» of the Swiss Academy of Sciences for initiating this series of lectures on the ethics of chemistry. I have been an advocate for ethics education for more than 20 years and the «Platform Chemistry» of the Swiss Academy of Sciences is the first national chemical society to recognize the importance of ethics by sponsoring this lectureship.

The University of Tennessee is located in Knoxville, which is in the Tennessee River Valley just to the west of the Great Smokey Mountains which you can see in the photo in Fig. 1. Unlike the Alps, the Smokies are an old, rather gentle mountain range, often shrouded in fog. Fig. 2 is a painting of the iconic building on our campus, Ayres Hall. The painting was done by Kelsey Roy, an alumnus of the College

${ }^{\star}$ Correspondence: Prof. J. Kovac Department of Chemistry College Scholars Program University of Tennessee Knoxville, TN 37996-1600, USA E-mail: jkovac@utk.edu

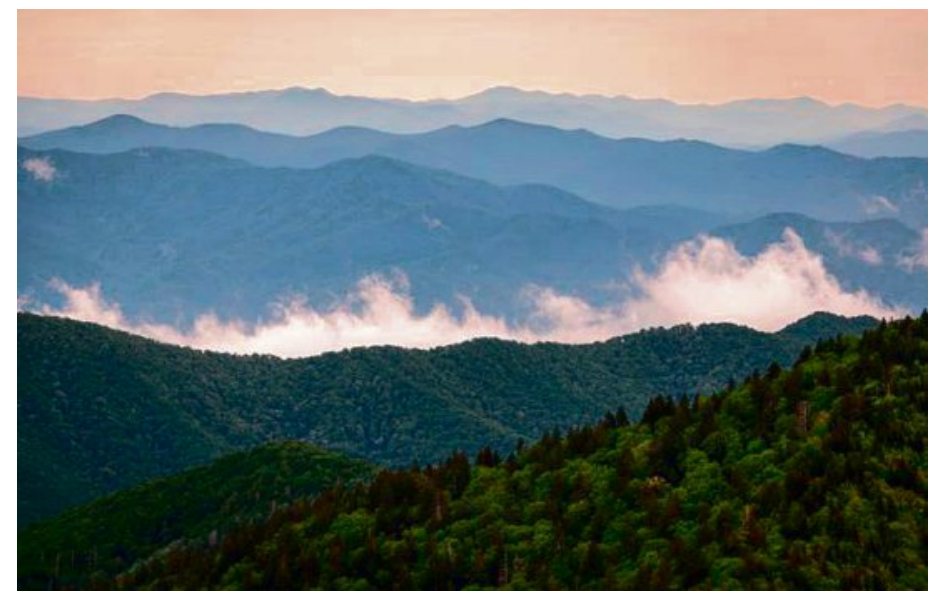

Fig. 1. The Great Smokey Mountains.

Scholars program which I have the pleasure of directing.

I was educated as a physical chemist. My only formal education in philosophy is four semesters during my undergraduate days at Reed College. When I began thinking seriously about ethics in science, I felt a bit like the poor guy in a cartoon I once saw in the New Yorker magazine, looking bewildered and reading Moral Values for Dummies, but I was able to find colleagues to help. They are all listed in the acknowledgments. Many are philosophers, a few are chemists and one is a lawyer, who is also my wife. I also need to acknowledge the Camille and Henry Dreyfus Foundation which gave me a small grant more than 20 years ago. That grant provided some summer salary and funds to pay a few undergraduate research assistants who helped me write the original version of 'The Ethical Chemist'. [1]

To begin, I need to identify the four characteristics of an ethical chemist. This list derives from the work of Michael Davis, a philosopher at the Illinois Institute of Technology, who is one of the leading scholars of professional ethics. ${ }^{\text {[2] }}$ The four characteristics are:
1. Understand the ideals and standards that govern professional moral decisions.

2. Understand the moral complexity of real-world situations.

3. Be able to design solutions to complex moral problems.

4. Have the moral courage to make difficult decisions, act on them, and to state them and the reasons for them publicly.

I will discuss each of these in detail.

The important term in the first characteristic is "professional ethics." To explain this I need to distinguish between common morality and professional ethics. Common morality consists of the more or less universal rules of human conduct that we expect all persons to obey, rules such as "don't lie," "don't kill," and "don't cause pain."'[3] I understand that there are variations in the interpretations of these rules in different societies, but the common morality is essential for human society to exist. We could not have a functioning society if everyone felt that they had license to lie all the time or to randomly murder their neighbors. These are the rules of conduct that we were all taught by our parents, teachers and ministers. We are all 
good at making day-to-day moral decisions. Those people who do not understand and practice the common morality often end up in prison.

Professional ethics is different. Common morality applies to everyone; professional ethics applies only to people who are members of a profession. When I use the word professional, I am thinking of the learned professions such as physicians, attorneys, clergy, and scientists. It is not enough just to be paid to be a member of a profession. A profession usually requires an advanced, specialized education and sometimes a license. Professionals work together to provide unique services to society. To facilitate the practice of their craft, professionals, formally or informally, adopt standards of conduct including codes of ethics. Professional ethics goes beyond the requirements of ordinary morality, the requirements of law, and the demands of the market. For example, physicians and lawyers have a strict rule of patient and client confidentiality, something that is essential to the responsible practice of their profession. As you will see later in this lecture, scientists have similar sorts of rules. Professional ethics must be consistent with the requirements of common morality. There cannot be a professional ethics of criminals because what they do is immoral.[4]

Following Michael Davis, I regard professional ethics as derived from the moral ideals which are at the core of the profession. ${ }^{[5]}$ The focus on moral ideals comes from the old idea of a profession as a "calling," work that you just cannot not do, something that is essential to your character. The moral ideal is the basis of the ideal of service that is essential to a profession. For example, the best attorneys adhere to the ideal of equal justice under law. Physicians really want to heal the sick and protect the public health. As noted, the moral ideal of a profession goes beyond ordinary morality but must be consistent with it.

Although the moral ideals of service professions such as law and medicine are relatively easy to state, the moral ideals for science are more complicated and I have spent a lot of time over the past several years thinking about this question and have developed a three-part statement of the moral ideals of science including chemistry. ${ }^{[6]}$

The first part concerns the integrity of the scientific process itself, the day-to-day work in the research group. This is the ideal that I call the "habit of truth." Because science is a form of public knowledge, we need an ideal for the relationships in the scientific community, which I regard as a gift economy. Finally, we need an ideal to govern the relationship between science and society. This is perhaps the

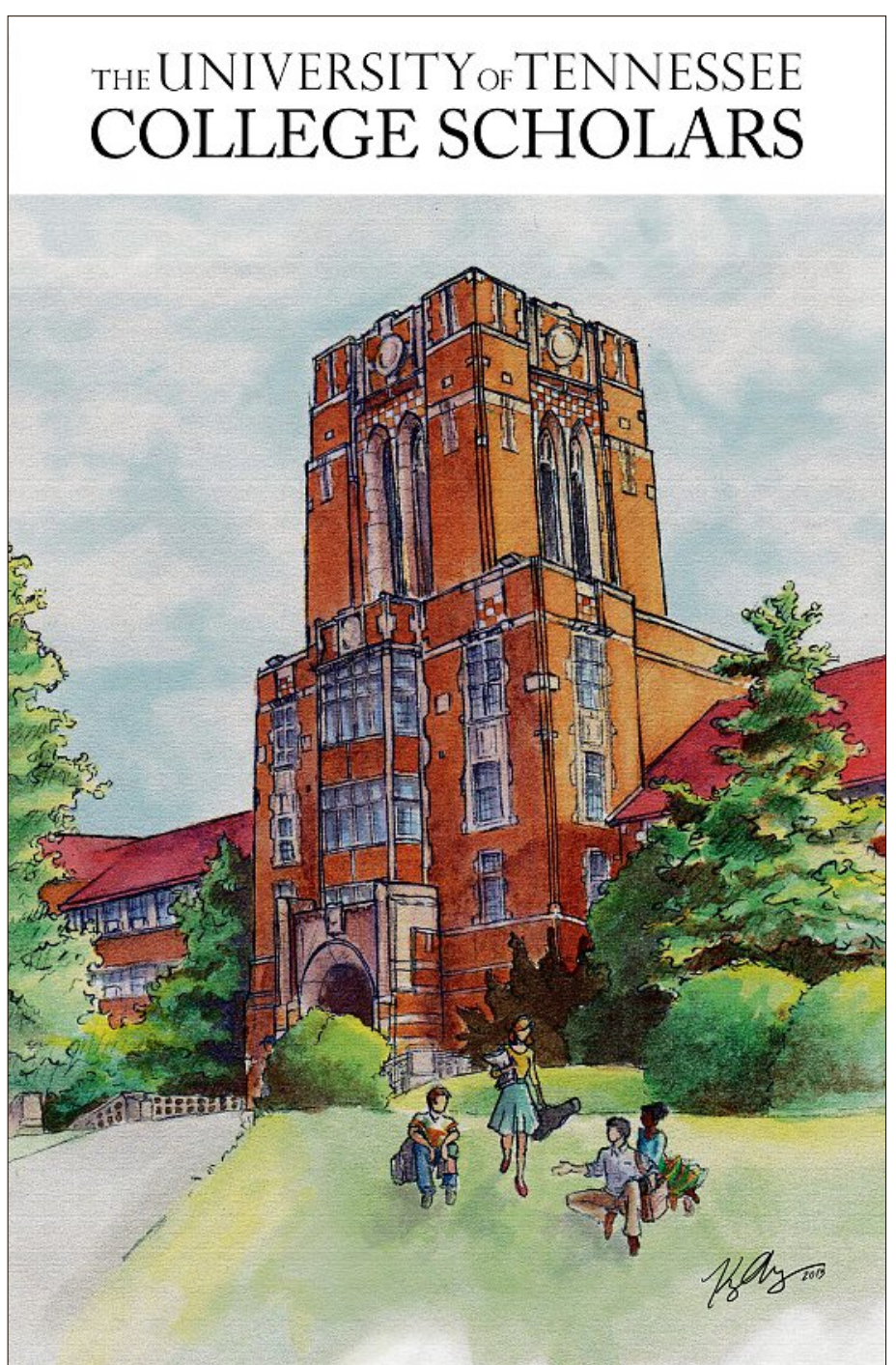

Fig. 2. Painting of Ayres Hall by Kelsey Roy. most controversial of the three, the ideal of shared-fate individualism. I will consider each of these in turn.

The phrase "the habit of truth" comes from the first book on ethics in science that I read, long ago when I was in high school, 'Science and Human Values', by Jacob Bronowski. ${ }^{[7]}$ Bronowski was one of the first people to go into Hiroshima after the atomic bomb was dropped and he wrote his book in part to come to terms with the horror he had seen. The idea is that what science is about is finding the truth, or at least reliable knowledge, about the natural world and this pursuit makes both technical or craft demands, but also requires scientists to adhere to strict ethical standards. Einstein, using the Old Testament language that he was fond of, called it finding the "secrets of the old one." All of us who have done scientific research understand how difficult it is, how easy it is to be fooled by nature. Two ways of thinking about the demands of research come from Richard Feynman who said,

"It's a kind of scientific integrity, a principle of scientific thought that corresponds to a kind of utter honesty a kind of leaning over backwards. In summary, the idea is to try to give all the information to help others to judge the value of your contribution, not just the information that leads to judgment in one particular direction or another." [8]

and P. W. Bridgeman who said, "The scientific method, as far as it is a method, is nothing more than doing one's damnedest with one's mind, no holds barred."[9]

Although the center of science, particularly chemistry, is the laboratory, which is where discoveries are made, science is a form of public knowledge. Discoveries must be communicated, usually in journal articles, and then scrutinized by the larger community. A new discovery or theory only becomes part of the body of scientific knowledge once it has been accepted, at least provisionally, by the community. This leads to the second part of the ideal: the gift economy.

I learned about the gift economy from my colleague, the philosopher of science, Davis Baird, who introduced me to Lewis Hyde's wonderful book, 'The Gift: Imagination and the Erotic Life of Property'. [10] 
This is a book I just had to read, if nothing else to find out what Hyde meant by "the erotic life of property."

We all live in two economies, the familiar commodity economy and the less familiar gift economy. The commodity economy is based on mutually beneficial interactions between people: fee for goods or fee for services. We all engage in such exchanges every day. We go to a store and buy a loaf of bread or a pair of shoes. You hand over the price and walk away with the product. You are not interested in establishing a personal relationship with the person behind the counter. You just want your baguette or your shoes.

The gift economy is different. To understand it, think about to whom you give gifts and why. You give gifts to family and close friends and you do so to establish or to maintain a personal relationship. When I pick out a gift for my wife, I think hard about what she would like, but also about a gift that will reflect the nature of our relationship. The gift is not just a tangible object, say a piece of jewelry, but as Emerson says, it is part of me as well.

In science we use the intellectual gifts of our colleagues, past and present, to make our own discoveries. This gift exchange creates a community. In accepting the gifts from others, we incur an obligation to contribute our own gifts to the community. These intellectual gifts are the result of human creativity. In the commodity economy, those who are most respected are those that have accumulated the most, but in the gift economy, those who are most respected are those who have contributed the most. Think about the chemists you most admire. Aren't they people like Linus Pauling or G. N. Lewis who laid the foundations of the science? We use their gifts all the time.

Finally, we need to think about the relationship between science and society. This is particularly important for chemistry which is a most useful science. The things that chemists make, medicines and materials, personal care products and agricultural chemicals, have made our lives better. The work we do in our laboratories is funded by governments, foundations and corporations because of the promise that what we discover will be useful. Of course, chemists and other scientists are also interested in the fundamental understanding of the natural world. These two motivations, fundamental understanding and considerations of use, have been considered by Donald Stokes in his book, 'Pasteur's Quadrant', where he introduced his quadrant model.[11] Stokes put the two motivations on two perpendicular axes and then, for simplicity, set up a binary scale - yes vs. no. The quadrant model is illustrated in Fig. 3.

\begin{tabular}{|c|c|c|}
\hline \multirow{3}{*}{$\begin{array}{l}\text { Quest for } \\
\text { fundamental } \\
\text { understanding? }\end{array}$} & $\begin{array}{c}\text { Consideration of } \mathrm{U} \\
\text { No }\end{array}$ & Yes \\
\hline & $\begin{array}{l}\text { Pure fundamental } \\
\text { research (Bohr) }\end{array}$ & $\begin{array}{l}\text { Use-inspired basic } \\
\text { research (Pasteur) }\end{array}$ \\
\hline & & $\begin{array}{l}\text { Pure applied } \\
\text { research (Edison) }\end{array}$ \\
\hline
\end{tabular}

Fig. 3. Quadrant model for scientific research.

Bohr's quadrant is the home of pure fundamental research, motivated by the quest for fundamental understanding with no thought about possible uses. As a theorist, this is where I spent most of my scientific career. Edison's quadrant on the lower right is what is usually called applied research. The goal is useful stuff with no particular interest in fundamental understanding. The most interesting quadrant is the one Stokes called Pasteur's quadrant, where the problems are practical, looking for useful results, but where the discovery of fundamental knowledge is part of the process. Much of chemistry is done in Pasteur's quadrant. My favorite historical example is the work of Wallace Hume Carothers at DuPont.[12] Carothers was interested in proving the macromolecular hypothesis, that polymers were covalently bonded long chains, but in the process he invented nylon. Both the chemistry community and DuPont were winners.

In thinking about either use-inspired basic research or applied research, the question is what projects should one engage in. This is a complicated question that depends on how much choice individual chemists have in what they do. Those employed in industry clearly have less choice than those who are in universities. No matter the particular situation, we can discuss the moral ideal.

About twenty years ago, Freeman Dyson expressed the concern that science is in trouble because of a poor choice of goals. [13] His rather strong indictment was, "As a general rule, to which there are many exceptions, science works for evil when its effect is to provide toys for the rich and works for good when its effect is to provide necessities for the poor." The essential message was that scientists were not sufficiently concerned with the overall public good. This concern was well articulated by the late philosopher, Norman S. Care, in his book, 'Decent People'.[14] Care puts forward a moral ideal he calls shared-fate individualism which derives from his concerns about the inequality in the contemporary world which is a contrast between great wealth and crushing poverty. Care is also concerned about the longterm fate of the planet and the human race. Care first defines what he calls competent individuals. These are people like you and me who are positioned both to selfrealize and to contribute to the lives of others. Care's position is that competent individuals must put other-responsibility ahead of self-realization in significant life decisions, such as career choice. I think this means that in choice of research problems, scientists should put service to others ahead of self-realization, whenever possible. In Dyson's words, necessities for the poor should have priority over toys for the rich.

Clearly, this is a complicated issue. For example, you might believe that climate change is the most important scientific problem confronting humanity. In my case, my education and training was in the statistical mechanics of liquids and polymers so my ability to make a contribution to the science related to climate change was minimal at best. The problems one works on depend on what you can actually do, what you can get funded, and, of course, what will ensure that you can continue to contribute. Remember that this is an ideal, not a rule, and only expresses our aspirations. We will discuss the constraints more fully later.

Moral ideals are important because they show what we are at our best, but it is useful to have moral rules that provide minimum standards for behavior. They tell us what we should do. Here are a few moral rules for science which provide more practical guidelines for behavior.

- Experimental and theoretical procedures must be reported accurately

- Data are complete and correct

- Prompt and open communication

- Objective (unbiased interpretation)

- Give credit where credit is due

There are certainly others, but these are some of the most important. ${ }^{[15]}$

Once we understand the moral ideals and rules of professional ethics, we then need to learn to apply them to the ethical problems that we encounter in the practice 
of science. This means that we need to recognize the moral complexity of realworld ethical situations. What is it that makes these problems challenging? I have identified at least eight factors.

1. Complex fact situations. Rarely are moral problems straightforward. Just understanding the facts can be difficult

2. Each of us is a citizen of a national society with a history, goals and ideals. With citizenship come obligations.

3. We all have institutional obligations that come from our employer.

4. We all belong to a professional community of scientists, in our case chemists, with a code of ethics.

5. We may have obligations to funding agencies.

6. We are all members of the human community with the moral obligations of all persons.

7. In some cases, we have religious beliefs and practices that might influence our decisions.

8. Finally, there is self-interest which includes such considerations as career advancement, respect of colleagues, financial and family concerns.

All of these can come into play in a particular moral decision. We only have time for a few examples, but I would be happy to discuss ethical problems that interest you in the discussion period after the lecture.

\section{Choosing a research project}

The moral ideal of shared-fate individualism suggests that all of us should be choosing research problems that will benefit humanity in some direct way. Of course, it is not that simple. First, the problem has to be something that you are professionally competent to address. You have to have the background, personnel, and equipment. Second, you have to get it funded so the priorities of the funding agencies come into play. You also have to consider your own career. Developing and maintaining a professional reputation is essential to success in science.

\section{Discarding a data point}

One of the ethical standards of science is that the data reported should be complete and correct, insofar as you know. It is possible that you have made a mistake, but you should not report data that you know to be incorrect, or even worse, data that have been fabricated. In reality, however, no one reports all the data. In any experimental project there is a lot of preliminary work, getting the reactions to proceed, getting the instruments working properly and the like.
None of this is reported and not reporting it is hardly unethical. But there comes a time when you begin taking "real data" and that should be reported. But, things do not always go smoothly. A reaction goes awry, a measurement is inconsistent with previous runs. This is where both professional judgment and ethics are tested. There are valid reasons for discarding a data point, such as statistical tests, but here your preconceptions can cause problems. Scientists often start an investigation with an idea of how things will go but that idea may be wrong and the data point that does not fit may be the evidence that your theory is wrong.

In Fig. 4 you see a graph of some data. These are not real data; I made them up for illustration. The research advisor thought that a particular response, on the y axis, would be linear in a stimulus which is on the $\mathrm{x}$ axis. The graduate student went into the lab and obtained the results shown. Most of the points support the linear hypothesis, but two of them are way off the line. What should the student do? The student could present all the data to the adviser, which we hope would stimulate a conversation about the outliers. Perhaps they should be discarded for a good chemical reason. Perhaps the student should go back to the lab and re-measure the points. This might be relatively easy, but suppose the measurements were made by neutron scattering and the experiments were done in Grenoble. For all of you, Grenoble is a short train trip away, but if you live in Knoxville, it is an expensive plane trip. It may not be feasible to repeat the experiment. Perhaps the outliers are actually telling us something new.

Another possibility is that, knowing that the research adviser is deeply committed to the linear hypothesis, the student might just leave those two points off the graph, telling him or herself, that they were mistakes. This would make life easier, but it would be dishonest.

An interesting historical example is the famous Millikan oil drop experiment.[16] Fig. 5 is a graph of Millikan's data. The black points are the ones that appeared in his paper; the white ones were not published. Millikan was certain that the electron had a discrete charge and he judged the quality of his data based on how well the calculated change conformed to this expectation. The experiment is very difficult and Millikan discarded many pieces of data based on his scientific judgment that something had gone wrong. In his article, he claimed that he reported all the data which was both untrue and unethical, but his judgment was sound. The history of science is filled with sad incidents where prior expectations led people astray. ${ }^{[17]}$

\section{Writing a scientific article or report}

The myth is that the scientific paper is a dispassionate recounting of an investigation. Nothing could be further from the truth. As Roald Hoffmann has argued in his article, 'Under the Surface of the Chemical Article,' scientific writing is a form of rhetoric, a human-made creation. ${ }^{[18]}$ An article is a form of persuasive writing. The authors are trying to convince the readers (and themselves) of both the truth and the importance of the discovery. They marshal their best arguments and minimize the loose ends, and there are almost always loose ends.

Another ethical issue is authorship. Who should be included as an author and in what order should the authors be listed? The basic criteria are that authors should have (1) made a significant intellectual contribution to the research, (2) be prepared to explain and defend the article, and (3) read and reviewed the paper. There is less agreement about the order of authors. My $\mathrm{PhD}$ advisor felt that the person who actually wrote the paper should be first. One of my colleagues at the University of Tennessee always put his name last on papers written with students. I once read a paper by two senior scientists which included the footnote, "The order of the authors was determined in a poker

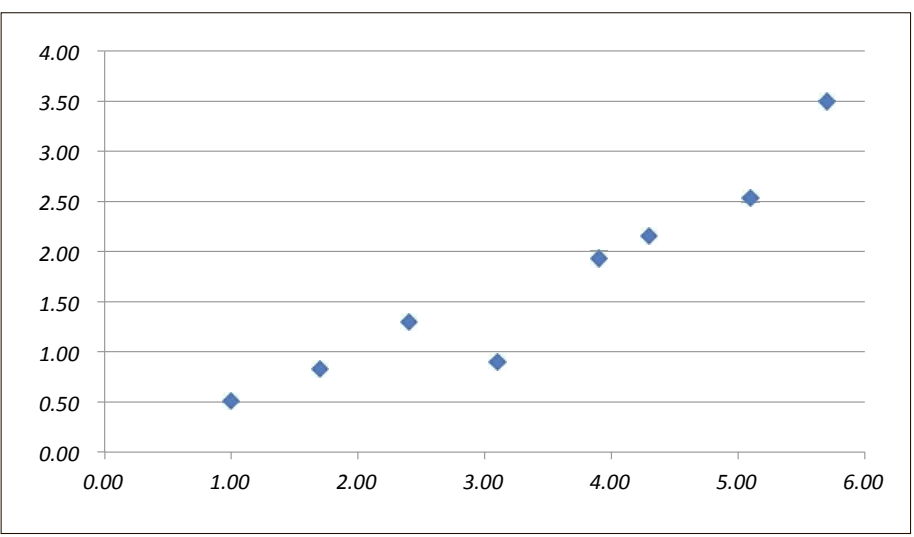

Fig. 4. Hypothetical data from an experiment. 
Fig. 5. Millikan's data from the oil drop experiment.

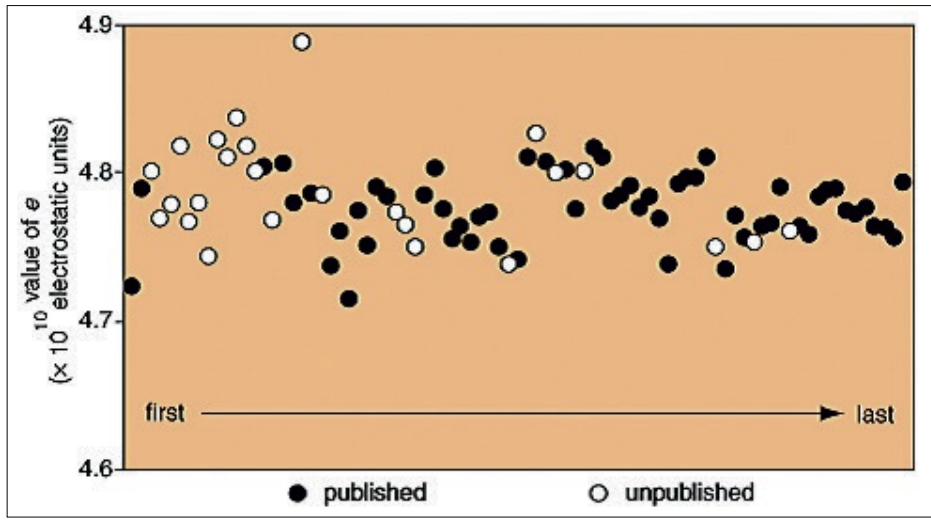

game." I have included the names of students on papers to which they had only made minor contributions because I wanted to help their careers. Sometimes it is difficult to decide what is fair, but it is essential to recognize what people contribute and not include authors who contributed nothing.

\section{Conflict of interest and conflict of commitment}

A conflict of interest occurs when some outside interest has a significant probability of affecting one's judgment. One important form of conflict of interest is financial, something that has become a problem in the biomedical sciences where researchers sometimes own stock or have equity interest in a company that funds their research. The researcher might be tempted to overemphasize the importance of his or her results, or even to falsify data, to increase the value of the stock. This could become a problem for chemistry because of the pressures to patent and commercialize the results of research.

Another, more subtle, conflict is between the interests of a university professor and the interests of graduate students and postdocs. Because of the differential power relationship there are several ways that research advisers can take advantage of students. For example, they can take credit for discoveries made primarily by students. A famous example, although not in chemistry, is the discovery of streptomycin for which Selman A. Waksman won the Nobel Prize in 1952. The discovery was actually made by a graduate student, Albert Schatz, but Waksman slowly removed Schatz's name from the story and claimed full credit. Waksman was awarded a patent and received royalties. There was a lawsuit which was settled and Schatz was acknowledged as a co-discoverer and received a share of the royalties. Schatz's lab notebooks were recently found and confirm his priority. ${ }^{[19]}$
Conflicts of commitment have to do with the amount of time that a scientist spends on various activities. For example, a university scientist might spend a significant amount of time on activities that are personally remunerative, such as consulting or working for a start-up company based on his or her research, while neglecting teaching and research direction responsibilities.

\section{Use of confidential information}

Working scientists are privy to confidential information mostly in the form of grant proposals and articles that they are asked to review. Using information from either of these in one's own work without permission is a serious violation of confidentiality.

After identifying and clarifying an ethical problem, we have to come up with a solution, a course of action. As noted by Caroline Whitebeck, "An ethics problem is not a multiple choice problem, rather it is a design problem. ${ }^{[20]}$ One must devise possible courses of action as well as evaluate them." Long ago, the British philosopher, Stuart Hampshire called attention to this rather neglected aspect of moral philosophy when he wrote, "The typical moral problem is not a spectator's problem or a problem of classifying or describing conduct but a problem of practical choice and decision.'[21]

The solution to an ethical problem must have the following characteristics.

1. It must achieve the desired end, if possible.

2. It must be consistent with relevant moral principles.

3. It should be reasonably secure against accidents or other miscarriages.

4. It should be consistent with background constraints. By background constraints, I mean things like one's personal situation. For example, if a course of action would result in losing a job when the person involved is supporting a family, might not be possible.

In evaluating various courses of action, you can use the three major ethical theories which emphasize different aspects of the moral life. Consequentialist, or utilitarian, theories regard actions as the primary bearer of moral value and ask whether the proposed action will result in more positive than negative consequences. This can be very difficult to determine. Deontological theories, at least in Kant's view, take motives, or intentions, as the primary bearer of moral value and ask whether this is an action that I would want every rational person to take in similar circumstances? In another view, Kant says that we should never use humans as means, but always as ends. Virtue theories regard a person's characteristics to be the primary object of moral assessment. Goodness is having the right feelings at the right times toward the right people in the right measure, between two extremes. Virtues are characteristics that need to be developed. Each of the major moral theories is monistic; they regard one thing as the object of moral assessment and therefore ultimately fail as complete moral theories because they lead to moral dilemmas that are not easily resolvable in the context of that theory.

Usually, there is more than one course of action that is morally allowed. The different choices each have different advantages and disadvantages. Even though there may not be an obvious right choice there are some choices that are morally unacceptable.

As an example, imagine that you are working in a laboratory that does environmental analyses such as looking at levels of toxic substances in drinking water. Your most recent analysis shows that the level of some substance in the local water supply is too high. When you show this result to your supervisor, he tells you to change the number so that it is lower than the maximum allowed. You have several possible courses of action: going up the chain of command and blowing the whistle publicly are two options. An option that is clearly unacceptable is poisoning your supervisor.

Many complex ethical problems do not have clean solutions because two deeply held moral principles are in conflict. A classic example is "would you lie to save a life?" Such problems require coping rather than solving.

Finally, living an ethical life requires the moral courage to make difficult decisions and to clearly state the reasons behind your decision. It can be difficult to do the right thing. I suspect that all of us have done something that we later regretted because of peer pressure, or not done something we 
probably should have because it was easier just to walk away.

What I hope I have convinced you of is that ethics is integral to science. We do not have science as one pursuit and ethics as a separate field study. Instead, they are intertwined and the decisions that we make as working chemists require both a careful consideration of both the technical and scientific issues and the ethical consequences.

\section{Appendix: Questions raised during discussions}

Each lecture was followed by a time for discussion. In some cases, the discussion lasted for 30 minutes or more. I have summarized some of the important issues that were raised.

Does the increased pressure for large numbers of publications result in more breaches of scientific ethics? Do chemists engage in questionable research and publication practices to increase their publication rate and their professional visibility? Several people pointed out that the use of metrics such as impact factors for journals and the h-index can lead to inappropriate behavior, such as cutting corners to publish more quickly and publishing many small papers rather than telling the complete story in a longer article (sometimes called salami science).

The limitations of the peer review system in detecting scientific misconduct are well documented. Are there ways to improve the system to do a better job of identifying possible misconduct? At least two problems were identified. One was that active researchers often receive more articles than they have time to carefully review. A second was that the articles are often so specialized that doing a good review will require a lot of time for background reading and studying the article in detail.

Students and younger faculty were concerned about the problem of balancing the desire to do research on significant problems, both pure and applied, which might only yield results after many years of work with the need to publish enough to establish a reputation and earn tenure in a university. The fast pace of contemporary chemistry leaves little time to think deeply. A related concern is how to sustain funding for such projects.

Although good data are not available, several discussants suggested that low-level unethical behavior might be widespread in chemistry and wondered what can be done to improve the "moral culture" of the chemical community. Several suggestions were made. As noted above, reducing or eliminating the use of questionable metrics such as the impact factor in favor of actually reading and evaluating the articles is one step. It is essential that research advisers provide an example of unimpeachable scientific integrity and manage their research groups accordingly. Finally, systematic, highquality ethics education should be part of all degree programs in chemistry.

\section{Acknowledgments}

I am grateful to the following people who have contributed to my work on ethics through the years: Davis Baird, the late Norman S. Care, Brian P. Coppola, Michael Davis, Don Gotterbarn, John Hardwig, Roald Hoffmann, Roger Jones, Christopher Pynes and Susan Davis Kovac. I also need to thank the Camille and Henry Dreyfus Foundation for providing the early financial support that led to the writing of 'The Ethical Chemist'.

Received: January 3, 2017
[1] J. Kovac, 'The Ethical Chemist: Professionalism and Ethics in Science', Pearson Prentice Hall, Upper Saddle River, NJ, 2004

[2] M. Davis, 'Ethics Across the Curriculum: Teaching Professional Responsibility in Technical Courses,' Teaching Philosophy 1993. 16, 205.

[3] See, for example, B. Gert, 'Common Morality: Deciding What to Do', Oxford University Press, Oxford and New York, 2004.

[4] M. Davis, 'Do the Professional Ethics of Chemists and Engineers Differ?' HYLE, 2002, $8,21$.

[5] M. Davis, 'The Moral Authority of a Professional Code' in Authority Revisited, Nomos XXIX, New York University Press, New York, 1987.

[6] J. Kovac, 'Moral Rules, Moral Ideals and UseInspired Research,' Science and Engineering Ethics 2007, 13, 159

[7] J. Bronowski, 'Science and Human Values', Harper Torchbooks, New York, 1956.

[8] R. P. Feynman, 'Surely You're Joking Mr Feynman', W. W. Norton, New York, 1985, p 341

[9] P. W. Bridgman, quoted in G. J. Holton, 'Victory and Vexation in Science: Einstein, Bohr, Heisenberg, and Others', Harvard University Press, Cambridge, 2005, p. 76.

[10] L. Hyde, 'The Gift: Imagination and the Erotic Life of Property', Vintage, New York, 1979.

[11] D. Stokes, 'Pasteur's Quadrant', Brookings Institution Press, Washington, DC, 1997.

[12] M. E. Hermes, 'Enough for One Lifetime: Wallace Carothers, Inventor of Nylon', American Chemical Society and Chemical Heritage Foundation, Washington, DC, 1996.

[13] F. Dyson, 'Can Science Be Ethical', New York Review of Books 1997, 44, 46.

[14] N. S. Care, 'Decent People', Rowman and Littlefield, Lantham, MD, 2000.

[15] See, for example, A. E. Shamoo, D. B. Resnik, 'Responsible Conduct of Research, Second Edition', Oxford University Press, Oxford and New York, 2009

[16] G. J. Holton, 'Subelectrons, Presuppositions, and the Millikan-Ehrenhaft Dispute', in G. J. Holton, 'The Scientific Imagination: Case Studies', Cambridge University Press, Cambridge, 1978.

[17] W. Gratzer, 'The Undergrowth of Science: Delusion, Self-Deception and Human Frailty', Oxford University Press, Oxford and New York, 2000.

[18] R. Hoffmann, 'Under the Surface of the Chemical Article', Angew. Chem. 1988, 27, 1593.

[19] M. Wainwright, 'Strepomycin: Discovery and Resultant Controversy', History and Philosophy of the Life Sciences 1991, 13, 97.

[20] C. Whitebeck, 'Ethics as Design: Doing Justice to Moral Problems', Hastings Center Report 1996, 26, 9 .

[21] S. Hampshire, 'Fallacies in Moral Philosophy', Mind 1949, 58, 466 